\section{AB0469 EVALUATION OF PILOCARPINE TREATMENT IN XEROSTOMIA BY PULSED DOPPLER COLOR ULTRASONOGRAPHY: ECHOPILO STUDY}

T. Depinoy ${ }^{1}$, A. Saraux ${ }^{1}$, S. Boisrame ${ }^{2}$, D. Cornec ${ }^{1}$, J.O. Pers ${ }^{3}$, T. Marhadour ${ }^{1}$ D. Guellec ${ }^{1}$, V. Devauchelle-Pensec ${ }^{1}$, S. Jousse-Joulin ${ }^{1} .{ }^{1}$ Rheumatology, Cavale Blanche Hospital; ${ }^{2}$ Odontology Department; ${ }^{3}$ Immunology Department, Morvan Hospital, Brest, France

Background: The ultrasonography of salivary glands (USSG) has proved its utility in diagnosing and following primary Sjögren patient's (pSS) $(1,2)$. The evaluation of disease activity is still of interest and can be studied by assessing the inflammatory status of SG using US Doppler.

Objectives: To evaluate the vascularization of salivary glands, and particularly the parotid gland (PG) using Pulsed Doppler color ultrasonography (USSGPD) in patients complaining of xerostomia before and after treatment by pilocarpine.

Methods: We prospectively included patients with objective dry mouth syndrome (using salivary flow rate) at Brest University Hospital (DiapSS cohort). The vascularization was assessed by the resistive index (RI) at the left parotid. Only patients with pathological $\mathrm{RI}(<0.8)$ were included in order to observe evolution after pilocarpine. USSGPD was carried out by the same operator. A dental consultation with measure of salivary flows before and after stimulation was performed. These examinations were performed at baseline and after 3 months of treatment with pilocarpine at $4 \mathrm{mg} 3$ times daily.

Results: Among the 19 patients included, 11 received pilocarpine treatment for the whole 3 months period, 6 of the 8 remaining patients stopped the pilocarpine due to side effects. Among the 11 patients with a follow-up evaluation at 3 months, 5 had pSS according to AECG criteria. The differences of RI before and after lemon stimulation were on average of -0.04 at baseline and -0.04 at M3. The sum of ultrasound's grades average of the four glands was 3.47 at M0 and 4.18 at M3. The non-simulated salivary flow was on average of $1.96 \mathrm{~mL} / \mathrm{mn}$ at $\mathrm{M} 0$ and 5.23 $\mathrm{mL} / \mathrm{mn}$ at M3, whereas the average of stimulated salivary flow was $2.84 \mathrm{~mL} / \mathrm{mn}$ at $\mathrm{M} 0$ and $8.51 \mathrm{~mL} / \mathrm{mn}$ at M3. None of these observed differences were statistically significant before and after 3 months of treatment by Pilocarpine: RI before and after lemon stimulation $(p=0.953)$, the sum of the four glands' grades $(p=0.858)$, the non-stimulated $(p=0.26)$ and stimulated salivary flow $(p=0.139)$. Concerning the 3 patients with Sjögren's syndrome, there was no differences using RI before and after treatment but the RI was lower in this subgroup compared to the xerostomia patients. The study was marked by a large number of pilocarpine's discontinuation $(31 \%)$ due to adverse effects.

Conclusions: Preliminary results showed no significant differences between the 4 gland's grade, ultrasound's RI and salivary non and stimulated flow before and after three months of pilocarpine's treatment. The vascularisation of salivary glands could be an opportunity to follow our treated patients with Sjögren's syndrome or with xerostomia but more studies are needed to prove the interest of this procedure.

References:

[1] Cornec D, et al. Contribution of salivary gland ultrasonography to the diagnosis of Sjögren's syndrome: toward new diagnostic criteria? Arthritis Rheum. 2013 Jan;65(1):216-25.

[2] Jousse-Joulin S et al. Brief Report: Ultrasonographic Assessment of Salivary Gland Response to Rituximab in Primary Sjögren's Syndrome. Arthritis Rheumatol. 2015 Jun;67(6):1623-8.

Acknowledgements: We thank the Professor luc Bressollette and Muriel Korpet for their contribution in the study.

Disclosure of Interest: None declared

DOI: 10.1136/annrheumdis-2017-eular.2937

\section{AB0470 RESPONSIVENESS OF SYSTEMIC LUPUS ERYTHEMATOSUS PATIENTS AFTER RITUXIMAB TREATMENT: A SINGLE CENTER EXPERIENCE}

Y.P. Tsao, C.Y. Tsai. Medicine, Taipei Veterans General Hospital, Division of Allergy, Immunology, Rheumatology (Air), Taipei, Taiwan, Province of China

Background: Systemic lupus erythematosus (SLE) is a complex disease with multi-organ presentations. Lupus nephritis, which results from autoantibody deposition at glomerulus, induces inflammation and damage. Lupus nephritis is also the leading cause of comorbidity in SLE patient and associated with poor prognosis.

Objectives: To evaluate the treatment responsiveness of rituximab in patients with SLE.

Methods: Patients should fulfill the criteria of 1997 American College of Rheumatology classification criteria for SLE. Patients underwent chemotherapy, with severe infection, under hemodialysis or after kidney transplantation were excluded. Total 37 patients were evaluated receiving rituximab infusion from 2009 to 2013. Clinical parameters were measured before and after rituximab usage.

Results: Among the 37 patients, the female patient was $89.2 \%$. Mean age was 39.53 years old. The mean creatinine level remained similar during the 36 months of follow-up. In the beginning of the treatment, the mean creatinine level was $1.40 \mathrm{mg} / \mathrm{dl}$ (SD 0.84). After 12, 24, 36 months of follow-up, the mean creatinine levels were $1.73 \mathrm{mg} / \mathrm{dl}, 2.16 \mathrm{mg} / \mathrm{dl}$, and $2.40 \mathrm{mg} / \mathrm{dl}$, respectively $(p=0.431,0.148$, 0.328 ). The mean proteinuria level was $3.51 \mathrm{~g} /$ day initially (SD 2.52 ), but it rapidly decreased to $1.60 \mathrm{~g} / \mathrm{dl}$ after 6 months of follow-up $(\mathrm{p}<0.001)$, and further decreased to $1.40 \mathrm{~g} /$ day, $1.12 \mathrm{~g} /$ day, and $0.90 \mathrm{~g} /$ day after $12,24,36$ months of follow-up $(p=0.001,0.002,0.012)$. The mean ds-DNA level was $216 \mathrm{IU} / \mathrm{ml}$ in the starting of the treatment, and it decreased to $97.04 \mathrm{IU} / \mathrm{ml}, 88.281 \mathrm{~J} / \mathrm{ml}, 94.61 \mathrm{~J} / \mathrm{ml}$ after $12,24,36$ months of follow-up ( $p=0.002,0.003,0.05)$. The C3 level revealed elevation after 36 months of follow-up. The mean C3 level was $70.63 \mathrm{mg} / \mathrm{dl}$ initially, and increased to $88.60 \mathrm{mg} / \mathrm{dl}, 90.65 \mathrm{mg} / \mathrm{dl}$, and $96.20 \mathrm{mg} / \mathrm{dl}$ after $12,24,36$ months of follow-up $(p<0.001,0.002,0.011)$. The platelet level remained similar from the beginning of the study to 36 months of follow-up $(269.97 \mathrm{~K} / \mathrm{cumm}$ to $253.5 \mathrm{~K} / \mathrm{cumm}$, $\mathrm{p}=0.929$ ). The improvement of proteinuria was significant and could be detected in 6 months, which had significant correlations with the reduction level in 24 months $(p<0.001)$. This suggested that early improvement of proteinuria may predict the further responsiveness.

Conclusions: Although the role of rituximab still remained controversial in the treatment of systemic lupus erythematosus, it showed positive effects in our single center's experience. Early response to rituximab was an important predictor of further sustained responsiveness and reduction of proteinuria and other clinical parameters.

Disclosure of Interest: None declared

DOI: 10.1136/annrheumdis-2017-eular.6648

\section{SLE, Sjögren's and APS - clinical aspects (other than treatment)}

\section{AB0471 WIDE HETEROGENEITY IN TREATMENT PROTOCOLS AND INAPPROPIATE USE OF PREDNISOLONE FOR ANTI-RO/LA ASSOCIATED-CONGENITAL HEART BLOCK: A SYSTEMATIC REVIEW OF 492 CASES}

A. Erden ${ }^{1}$, L. Kilic ${ }^{1}$, E. Bilgin ${ }^{2}$, A. Fanouriakis ${ }^{3}$, S. Ceylan ${ }^{2}$, B. Hymabaccus ${ }^{2}$, Y.Z. Sener ${ }^{2}$, F. Gurler ${ }^{2}$, A. Sari ${ }^{1}$, B. Armagan ${ }^{1}$, O. Karadag ${ }^{1}$, S. Kiraz ${ }^{1}$, D. Boumpas ${ }^{3}$, U. Kalyoncu ${ }^{1} .{ }^{1}$ Department of Rheumatology; ${ }^{2}$ Department of Internal Medicine, Hacettepe University Faculty of Medicine, Ankara, Turkey;

${ }^{3}$ Rheumatology and Clinical Immunology, 4th Department of Internal Medicine, "Attikon" University Hospital, Athens, Greece

Background: Congenital heart block $(\mathrm{CHB})$ risk is $1-2 \%$ in case of maternal anti SSA/Ro and/or anti SSB/La antibody positivity. CHB have significant mortality (20-30\%) and available therapeutic options' efficacy is contradictory.

\begin{tabular}{|c|c|c|c|}
\hline \multicolumn{4}{|l|}{ 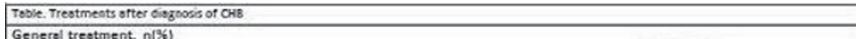 } \\
\hline \multicolumn{4}{|l|}{ 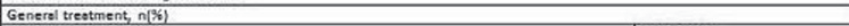 } \\
\hline Only glucocorticoids & \multicolumn{3}{|l|}{$92(39.3)$} \\
\hline Glucocorticoids and IVIG & \multicolumn{3}{|l|}{$10(4.2)$} \\
\hline Only IVIG & \multicolumn{3}{|l|}{$2(0.8)$} \\
\hline Glucocorticoids and hydroxychloroquine $(\mathrm{HCQ})$ & \multicolumn{3}{|l|}{$2(0.8)$} \\
\hline Glucocorticoids, HCQ and IVIG & \multicolumn{3}{|l|}{$2(0.8)$} \\
\hline Only HCQ & \multicolumn{3}{|l|}{$1(0.4)$} \\
\hline No treatment & \multicolumn{3}{|l|}{$134(57.2)$} \\
\hline \multicolumn{4}{|l|}{ Glucosorticoid type, $n(\%)$} \\
\hline Dexamethasone & \multicolumn{3}{|l|}{$54(50.9)$} \\
\hline Prednisolone & \multicolumn{3}{|l|}{$27(25.4)$} \\
\hline Betamethazone & \multicolumn{3}{|l|}{$11(10.3)$} \\
\hline Not known & \multicolumn{3}{|l|}{$14(13.2)$} \\
\hline \multicolumn{4}{|l|}{ Doxing regimen of s.jucosorticoids, $n[\xi]$} \\
\hline Dexamethasone $4 \mathrm{mg} / \mathrm{day}$, until birth & \multicolumn{3}{|l|}{$25(30.4)$} \\
\hline Prednisolone $40-60 \mathrm{mg} / \mathrm{day}$, untilbirth & \multicolumn{3}{|l|}{$11(13.4)$} \\
\hline $\begin{array}{l}\text { Dexamethasone but not knav dosage or time period } \\
\text { Dexamethasone or Betamethasone cumulative dose over } 100 \mathrm{mg}^{\prime} \text { ' }\end{array}$ & \multicolumn{3}{|l|}{$\begin{array}{l}9(10.9) \\
7(8.5)\end{array}$} \\
\hline Dexamethasone $8 \mathrm{mg} /$ day until birth & \multicolumn{3}{|l|}{$5(6.0)$} \\
\hline Dexamethasone or Betamethasone cumulative dose over $100 \mathrm{mg}^{\prime} \mathrm{s}^{\prime}$ & \multicolumn{3}{|l|}{$3(3.6)$} \\
\hline Dexamethasone $2 \mathrm{mg} / \mathrm{day}$, until birth & \multicolumn{3}{|l|}{$3(3.6)$} \\
\hline Prednisolone untilbirth, dosage not specified & $3(3.6)$ & & \\
\hline Prednisolone $10 \mathrm{mg} / \mathrm{day}$, untilbirth & $2(2.4)$ & & \\
\hline Dexamethasone $12 \mathrm{mg} /$ week, until birth & $2(2.4)$ & & \\
\hline Dexamethasone or Betamethasone $12 \mathrm{mg} / \mathrm{day}$, until birth & $2(2.4)$ & & \\
\hline Dexamethasone or Betamethasone $25 \mathrm{mg} /$ twice a week, until birth & $1(1.2)$ & & \\
\hline Dexamethasone $10 \mathrm{mg} / \mathrm{day}$, until birth & $1(1.2)$ & & \\
\hline Dexamethasone $6 \mathrm{mg} / \mathrm{day}$, untilbirth & $1(1.2)$ & & \\
\hline Prednisolone $2 \mathrm{mg} / \mathrm{kg} / \mathrm{day}$, no time period & $1(1.2)$ & & \\
\hline Use of betomimetics, $n(S)$ & & & \\
\hline Yes & $17\{12,4\}$ & & \\
\hline No & $120\langle 87.6\}$ & & \\
\hline Dosing regimen of N/G, $n(\%)$ & & & \\
\hline $0.4 \mathrm{gr} / \mathrm{kg} / \mathrm{day}$ for 5 days, then one per month or $1 \mathrm{~g} / \mathrm{kg} 2$ consequent day in a month & $4(28.6)$ & & \\
\hline $1 \mathrm{gr} / \mathrm{kg}$ perweek & $3(21.4)$ & & \\
\hline $0.4 \mathrm{gr} / \mathrm{kg}$ per 3 weeks & $3(21.4)$ & & \\
\hline $1 \mathrm{gr} / \mathrm{kg}$ per 3 weeks & $2(14.3)$ & & \\
\hline $1 \mathrm{gr} / \mathrm{kg}$ per 15 days until birth & $1(7.1)$ & & \\
\hline $1 \mathrm{gr} /$ day for 2 timestotally & $1(7.1)$ & & \\
\hline CHB type, $n[36)$ & Toking gluce & corticoids? & p \\
\hline & Yes & No & \\
\hline First degree block & $6(32)$ & $13(68)$ & 0.6 \\
\hline Second degree block & $5(18)$ & $22(82)$ & \\
\hline Third degree block & $46(20)$ & $185(80)$ & \\
\hline Sinus bradycardia & $5(26)$ & $14(74)$ & \\
\hline Total & $62\langle 21\}$ & $234\langle 79$ & \\
\hline Piasma exchange schedule n[(Y) & & & \\
\hline Two consequtive days, then weekly & $13(61.9)$ & & \\
\hline Totally 3 plasma exchanges in 48 hours, 1 cycle & $2(9.5)$ & & \\
\hline Totally 3 plasma exchanges in 48 hours, 2 cycles & $1(4.7)$ & & \\
\hline Totally 3 plasma exchanges in 48 hours, one per 4 weeks & $2(9.5)$ & & \\
\hline Totally 3 plasma exchanges in 48 hours, one per 3 weeks & $1(4.7)$ & & \\
\hline Unknown time period & $2(9.5)$ & & \\
\hline
\end{tabular}

